\title{
Hygrothermal Aging of Polyimide Matrix Composite Laminates
}

\author{
Man-Hee Han and John A. Nairn \\ Material Science and Engineering, University of Utah, Salt Lake City, Utah 84112, USA
}

\begin{abstract}
Two polyimide-matrix systems (Avimid ${ }^{\circledR}$ K3B/IM7 and PETI-5/IM7) were subjected to a series of hygrothermal aging experiments at various temperatures and relative humidities. For each aging condition, we measured water absorption rate and the microcracking toughness as a function of aging time. The toughness decreased with time. The rate of decrease increased with temperature and relative humidity. All experimental results could be fit to a simple first-order kinetics analysis where the degradation rate was assumed to be proportional to the total exposure to water above a threshold water level. Below the water threshold, no degradation occurred. The kinetics analysis was used to construct a hygrothermal aging master plot that can be used to make predictions of toughness degradation due to arbitrary hygrothermal environments. The master plot can be constructed from a few experiments on specimens immersed in water and thus is a potential accelerated test method for characterizing hygrothermal stability of composite laminates.
\end{abstract}

Keywords: Hygrothermal aging; microcracking toughness; master plot; accelerated test method; hygrothermal stability.

\section{Introduction}

Various types of polyimide-matrix composites are being considered for use in high temperature applications such as for supersonic aircraft. It was previously observed, however, that some polyimide laminates can spontaneously microcrack when exposed to hot and wet environments [1]. For example, when quasi-isotropic, Avimid ${ }^{\circledR}$ K3B/IM7 laminates were immersed in water at temperatures ranging from $35^{\circ} \mathrm{C}$ to $95^{\circ} \mathrm{C}$, the water uptake initially had Fickian behavior, but later, after apparently reaching an equilibrium level of water saturation, showed a non-Fickian jump in uptake rate. Microscopy results showed that the secondary uptake process was caused by spontaneous formation of matrix microcracks in $90^{\circ}$ plies despite the absence of any externally applied load. The time to initiate water-induced microcracks ( $t_{m}$ in minutes) as a function of temperature ( $T$ in Kelvin) was

$$
\ln t_{m}=\frac{3423}{T}+1.35
$$

which translates to an apparent activation energy of $28 \mathrm{~kJ} / \mathrm{mol}$. For example, when immersed in $80^{\circ} \mathrm{C}$, water-induced microcracks initiated in about 1,000 hours [1].

Spontaneous microcracking is caused by water-induced degradation of the toughness of the polyimide composite material [1]. Eventually, the toughness drops enough that microcracks can form due to residual stresses alone. In this paper we report results of monitoring the kinetics of the degradation in microcracking properties prior to and following the onset of spontaneous 
microcrack formation. The experiments include results for two different polyimide materials. For one material, experiments were done for water immersion, for exposure to various levels of humidity, and for various temperatures. All results can be interpreted with a simple kinetics analysis in which degradation rate depends on the integrated exposure to water. The kinetics scheme was used to derive an effective water-exposure time that was then used to generate a master plot for hygrothermal stability. The master plot can be used to predict toughness degradation following exposure to any hygrothermal aging conditions.

\section{Materials and Methods}

The two laminate materials used where DuPont Avimid ${ }^{\circledR}$ K3B/IM7 carbon fiber and PETI-5/IM7 carbon fiber composites. Each of these materials was laminated into $\left[0 / 90_{2}\right]_{s}$ cross-ply laminates and supplied to us by the Boeing Company. For hygrothermal aging experiments, a series of laminates $12.7 \mathrm{~mm}$ wide, $150 \mathrm{~mm}$ long, and $0.76 \mathrm{~mm}$ thick were dried at $120^{\circ} \mathrm{C}$ to remove moisture and then placed in a test tube either immersed in water or suspended over a salt solution $[2,3]$ to provide a constant relative humidity environment. While aging, the moisture content was periodically recorded. After selected aging times, specimens were removed, re-dried at $120^{\circ} \mathrm{C}$, and subjected to microcracking experiments, described below, to measure the microcracking toughness as a function of aging time. For Avimid ${ }^{\circledR} \mathrm{K} 3 \mathrm{~B} / \mathrm{IM} 7$ laminates, experiments at $80^{\circ} \mathrm{C}$ were done for immersed samples and for sample at $76 \%, 50 \%$, and $26 \%$ relative humidities. Additional experiments were done for immersed samples at $60^{\circ} \mathrm{C}$ and $43^{\circ} \mathrm{C}$. For PETI-5/IM7, the only experiments done were for samples immersed in water at $80^{\circ} \mathrm{C}$.

\section{Microcracking Experiments and Analysis}

To determine the toughness as a function of aging time, we measured the density of microcracks as a function of applied load. For each aging condition, three separate specimens were dried, tabbed with aluminum end tabs, and loaded at room temperature at $0.01 \mathrm{~mm} / \mathrm{sec}$ in a $25 \mathrm{kN}$ MTS servo-hydraulic testing frame. The loading was periodically interrupted and the specimens were removed and observed on edge by optical microscopy to record the density of microcracks in the $90^{\circ}$ plies. The resulting data were analyzed using the finite fracture mechanics methods described in Refs. [4-8] to determine microcracking fracture toughness denoted as $G_{m c}$. Note that all microcracking toughness tests were done at room temperature on dry specimens. Although elevated temperatures and moisture-induced stresses affect the microcrack formation during aging, those conditions are not relevant to the analysis of the room-temperature, dry toughness tests. The toughness tests assess the effects of all prior aging on laminate properties.

In brief, the microcracking analysis assumes the next microcrack forms when the energy released by formation of that microcrack exceeds the critical energy release rate or toughness for microcracking, $G_{m c}$, of the material. By an energy criterion, the applied stress as a function of microcrack density can be shown to follow $[4,7,9]$ :

$$
\sigma_{0}=\frac{1}{k_{m, 1}} \sqrt{\frac{G_{m c}}{G_{\text {unit }}(f \rho)}}-\frac{k_{t h, 1}}{k_{m, 1}} \Delta T
$$

where $k_{m, 1}$ and $k_{t h, 1}$ are mechanical and thermal stiffnesses for the $90^{\circ}$ plies (i.e., the mechanical and thermal stresses in the loading direction in the $90^{\circ}$ plies of the undamaged laminate are $\sigma_{m, 1}=$ $k_{m, 1} \sigma_{0}$ and $\left.\sigma_{t h, 1}=k_{t h, 1} \Delta T\right), G_{u n i t}(f \rho)$ is the energy release rate for formation of a microcrack in 
an interval of dimensionless size $f \rho$ when there is unit load in the $90^{\circ}$ plies, $f$ is a factor to account for non-uniform density of microcrack spacings [7], $\rho=1 /\left(2 t_{1} D\right)$ is a dimensionless microcrack spacing where $t_{1}$ is the semi-thickness of the $90^{\circ}$ plies and $D$ is the microcrack density, and $\Delta T$ is the difference between the test temperature and the laminate stress free temperature. The ply stiffness can be found by laminated plate theory [6] or, with sufficient accuracy, by 1D mechanics analysis:

$$
\begin{aligned}
k_{m, 1} & =\frac{E_{T}}{E_{c}^{0}} \\
k_{t h, 1} & =-\frac{E_{T} E_{A}\left(1-V_{1}\right) \Delta \alpha}{E_{c}^{0}}
\end{aligned}
$$

where $E_{T}$ and $E_{A}$ are the transverse and axial moduli of the ply material, $E_{c}^{0}$ is the modulus of the undamaged laminate in the loading direction, $V_{1}$ is the volume fraction for the $90^{\circ}$ plies, and $\Delta \alpha=\alpha_{T}-\alpha_{A}$ is the difference between the transverse and axial thermal expansion coefficients of the ply material.

Equation (2) is an exact energy analysis including all effects of residual stresses on the fracture process [10]. The result, however, is expressed in terms of $G_{\text {unit }}(f \rho)$, which can be expressed as $[4,8]$ :

$$
\begin{aligned}
G_{\text {unit }}(f \rho) & =\frac{f \rho B}{2}\left(\frac{E_{c}^{0}}{E_{T}}\right)^{2}\left[\frac{1}{E_{c}(f \rho / 2)}-\frac{1}{E_{c}(f \rho)}\right] \quad \text { load control } \\
G_{\text {unit }}(f \rho) & =\frac{E_{c}(\rho) E_{c}\left(\frac{\rho L}{L+2 \rho t_{1}}\right)}{E_{T}^{2}} \frac{f \rho B}{2}\left[\frac{1}{E_{c}(f \rho / 2)}-\frac{1}{E_{c}(f \rho)}\right] \quad \text { displacement control }
\end{aligned}
$$

Here $B$ and $L$ are laminate thickness and length and $E_{c}(\rho)$ is the axial modulus of the laminate as a function of microcrack spacing $\rho$. The two different expressions for load control vs. displacement control are a consequence of the discrete formation of complete microcracks [5]. For all laminates tested here, the differences between these two equations are small; all analyses were done with the load control expression. The $f$ term is also a consequence of the discrete nature of the microcracking process. All equations are developed for periodic arrays of microcracks, but during a series of microcracking events, the actual microcrack interval where new cracks form will statistically range between the current average crack spacing and twice the average crack spacing. On average, therefore, the microcracking interval should be 1.5 times larger than the mean crack spacing, but the specific $f$ for real specimens with statistical variations in properties might differ from 1.5. The use of $f$ to account for non-uniform crack spacings is well reinforced by experiments and computer simulations [4]; both results show that using $f=1.3$ to 1.5 provides an excellent approximation to accounting for non-uniform crack spacing. Here $f$ was treated as a parameter to improve fits at high crack density ( $f$ does not affect the anlaysis at low crack density); all results were fit best with $f$ between 1.3 and 1.65. Finally, the analysis requires calculation of $E_{c}(\rho)$. Any sufficiently-accurate analysis method can be used, but all calculations in this paper were based on complementary energy based methods to find modulus [11]. This analysis method has previously been shown to give excellent results for analysis of microcracking experiments [7].

Assuming the level of residual stresses $(\Delta T)$ can be estimated from the processing conditions, the only unknown parameter in Eq. (2) is $G_{m c}$ or the microcracking fracture toughness. By fitting experimental results to Eq. (2), one can therefore determine $G_{m c}$; here we determined $G_{m c}$ as a function of aging conditions. For early stages of aging, the laminates had no microcracks prior to 
the microcracking toughness determination. For these laminates, the toughness was determined by loading the laminates, recording the number of microcracks is the $90^{\circ}$ plies as a function of stress, and fitting to Eq. (2). For longer aging times, many laminates developed spontaneous microcracks. Because Eq. (2) includes residual stress effects, it was often possible to determine $G_{m c}$ by similar experiments. The fitting procedure, however, got harder and less accurate as the number of spontaneous microcracks increased. The specimens with a large number of spontaneous microcracks were the specimens with low toughness. We estimated $G_{m c}$ of these specimens by solving Eq. (2) for $G_{m c}$ and calculating the toughness from the microcrack density of spontaneous microcracks when $\sigma_{0}=0$. The toughness for theses conditions was always low or effectively zero toughness when compared to the toughness of unaged material.

\section{Results}

\section{Avimid ${ }^{\circledR}$ K3B/IMr Laminates}

The samples were aged under various conditions. During aging, we periodically weighed the specimens and recorded the amount of water uptake as a function of time. The results in Fig. 1 give the amount of water uptake as a function of immersion time for a series of Avimid ${ }^{\circledR}$ K3B/IM7 laminates that were immersed in water or exposed to various levels of relative humidity at $80^{\circ} \mathrm{C}$. The percent weight gain was calculated as

$$
\frac{W_{w e t}-W_{d r y}}{W_{d r y}} \times 100
$$

where $W_{\text {wet }}$ is the weight of the wet sample and $W_{d r y}$ is the weight of the dry sample. The smooth lines are fits assuming Fickian diffusion. The analysis assumed one-dimensional diffusion into a strip. The diffusion constants $(D)$ were calculated from the fits. The results for water immersion and for all humidities at constant temperature could be fit with the same diffusion constant of $D=8.3 \times 10^{-13} \mathrm{~m}^{2} / \mathrm{sec}$.

The time to reach saturation level was about 100 hours for all conditions. The average saturation weight gains (in \%) from two samples at each condition were $0.432 \%$ for water immersion, $0.376 \%$ for $76 \% \mathrm{RH}, 0.280 \%$ for $50 \% \mathrm{RH}$, and $0.121 \%$ for $26 \% \mathrm{RH}$. The relative weight gains, defined as the total weight gain divided by the weight gain for water immersion, were 0.87 for $76 \% \mathrm{RH}$, 0.65 for $50 \% \mathrm{RH}$, and 0.28 for $26 \% \mathrm{RH}$. The relative weight gains were approximately equal to the relative humidities. Furthermore, the stated relative humidities are nominal humidities that were taken from solution results in Refs. [2] and [3], but the conditions used here (namely $80^{\circ} \mathrm{C}$ ) were outside the conditions for that work. Our actual humidities may differ from the nominal humidities. Perhaps the relative weight gains provided a better measure of the effective relative humidities during the experiments.

Some raw microcracking results from Avimid ${ }^{\circledR}$ K3B/IM7 polymer laminates for microcracking density as a function of applied load following immersion in water at $80^{\circ} \mathrm{C}$ for various amounts of time are plotted in Fig. 2. The raw data clearly shifts to the left from the microcracking data of the unaged sample (filled symbols) with aging time indicating a significant drop in microcracking toughness with exposure time. After 200 hours of aging there were some initial microcracks, but additional microcracks formed during subsequent loading. Samples with aging times of 500, 800, and 1000 hours were nearly saturated in microcracks before mechanical testing and subsequent mechanical loading caused very few additional microcracks. The smooth lines in Fig. 2 are the fracture mechanics analysis (i.e., fits to Eq. (2)) used to determine $G_{m c}$ as a function of aging 


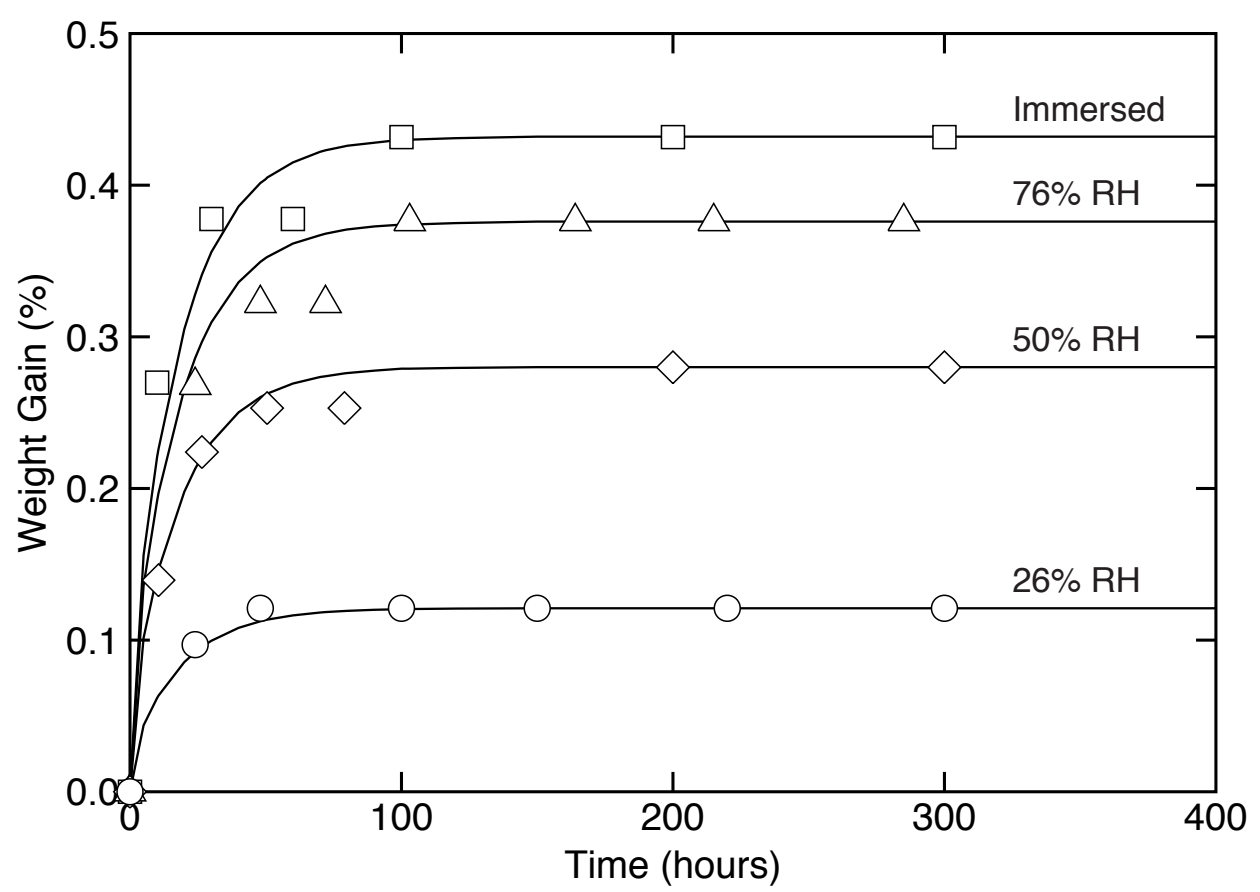

Fig. 1. Percentage weight gain for Avimid ${ }^{\circledR}$ K3B/IM7 laminates as a function of time when immersed in water or when exposed to various levels of relative humidity. The smooth lines are fits to the experiments assuming Fickian diffusion into a strip.

time. The transversely-isotropic ply properties used in the microcracking analysis were: $E_{A}=$ $134 \mathrm{GPa}, E_{T}=9.8 \mathrm{GPa}, G_{A}=5.5 \mathrm{GPa}, \nu_{A}=0.4, \nu_{T}=0.42, \alpha_{A}=-0.09 \mathrm{ppm} / \mathrm{K}, \alpha_{T}=$ $28.8 \mathrm{ppm} / \mathrm{K}$, and ply thickness $=0.158 \mathrm{~mm}$. All fits assumed $\Delta T=-225^{\circ} \mathrm{C}$ which was taken from the difference between the processing temperature $\left(350^{\circ} \mathrm{C}\right)$ and room temperature. The same temperature difference was used before to fit results for unaged K3B/IM7 laminates [6, 12]; a different $\Delta T$ would change the toughness results slightly, but would not change any of the kinetics analyses. The unaged material had a toughness of $G_{m c}=960 \mathrm{~J} / \mathrm{m}^{2}$; this toughness rapidly dropped with aging time. The specimens with aging times greater than 500 hours have no smooth lines. It was difficult to unambiguously fit these flat results to find $G_{m c}$, but it was possible to determine that the toughness must be very low $\left(<50 \mathrm{~J} / \mathrm{m}^{2}\right)$ by solving Eq. (2) for $G_{m c}$ with $\sigma_{0}=0$.

The experiments in Fig. 2 were for specimens immersed in water at $80^{\circ} \mathrm{C}$. The same types of experiments were repeated for specimens aged at $80^{\circ} \mathrm{C}$ but under relative humidities of $76 \% \mathrm{RH}$, $50 \% \mathrm{RH}$, and $26 \% \mathrm{RH}$. Figure 3 plots $G_{m c}$ as a function of aging time under relative humidity conditions in comparison to the aging results for the water-immersion. The smooth lines are fits to the kinetics model in the next section. The drop in toughness for water immersion was very fast. The toughness dropped to essential zero after only 500 hours of aging. The rate of the drop in toughness slowed down as the humidity level got lower. At the lowest humidity of $26 \%$, there was no sign of toughness drop in the first 1000 hours of aging.

To investigate the effect of aging temperature, the water-immersion experiments were repeated for specimens aged at $60^{\circ} \mathrm{C}$ and $43^{\circ} \mathrm{C}$. Figure 4 plots the results for $G_{m c}$ as a function of aging time for Avimid ${ }^{\circledR}$ K3B/IM7 laminates immersed in water, but at the three aging temperatures. The smooth lines are fits to the kinetics model in the next section. The degradation rate got slower at lower temperature. In addition, there appeared to be a threshold aging time. Before the threshold aging time, the toughness remained constant. After reaching the threshold time, the toughness 


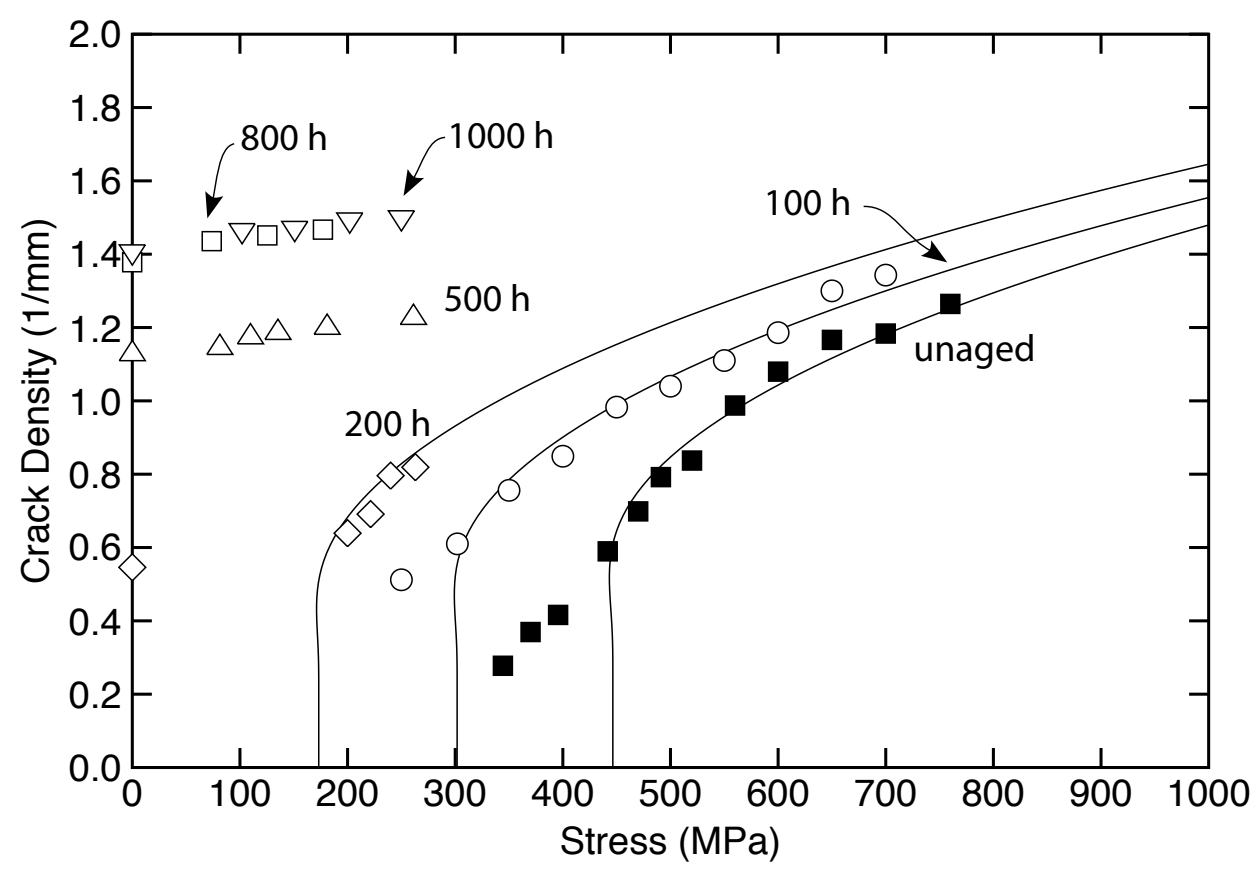

Fig. 2. The density of microcracks as a function of applied stress for unaged (filled symbols) and aged Avimid ${ }^{\circledR}$ K3B/IM7 laminates. The aging was for various amounts of time at $80^{\circ} \mathrm{C}$ while immersed in water. The smooth lines are fits to microcracking theory which were used to determine microcracking toughness as function of aging time.

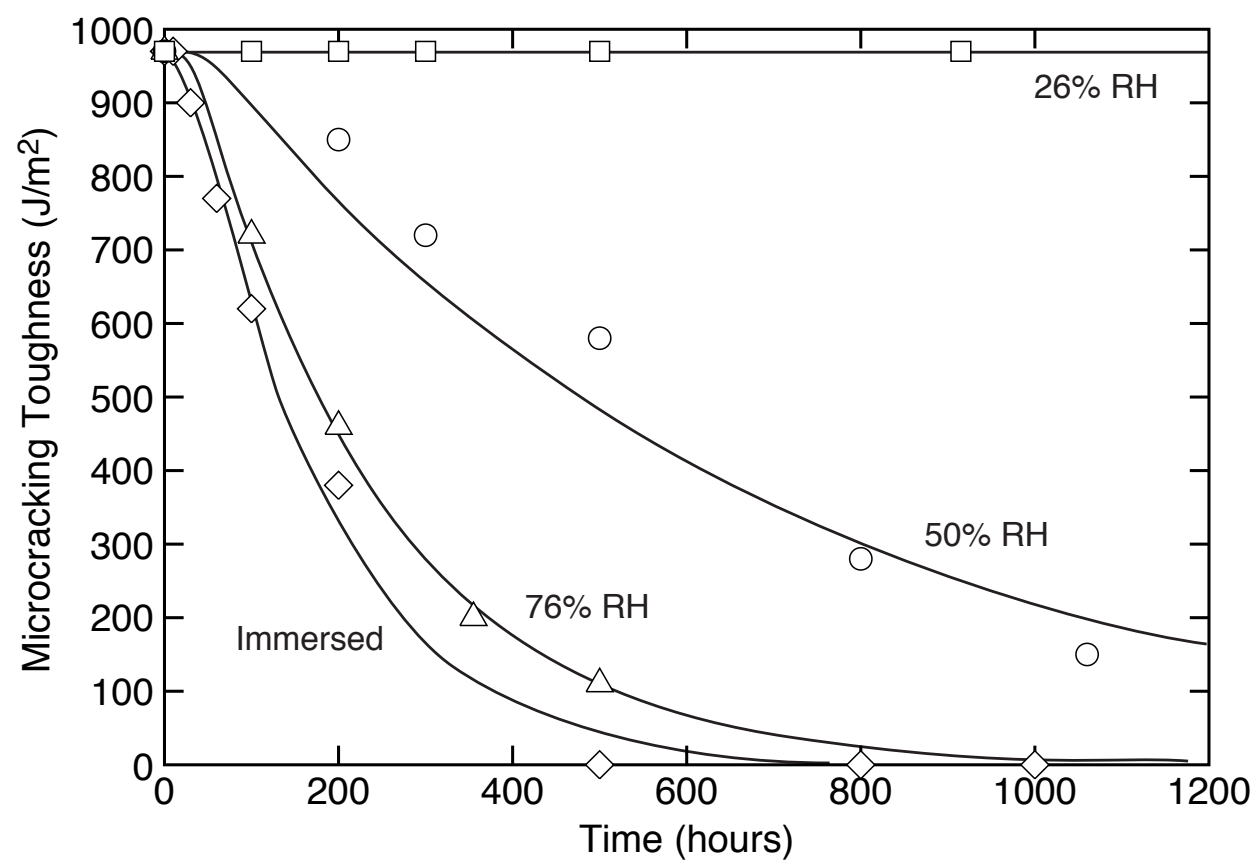

Fig. 3. The microcracking toughness, $G_{m c}$ as a function of aging time for Avimid ${ }^{\circledR}$ K3B/IM7 laminates at $80^{\circ} \mathrm{C}$ for water immersion or for various levels of relative humidity. The smooth lines are fits to first-order hydrolysis analysis with threshold water concentration for the onset of degradation. 


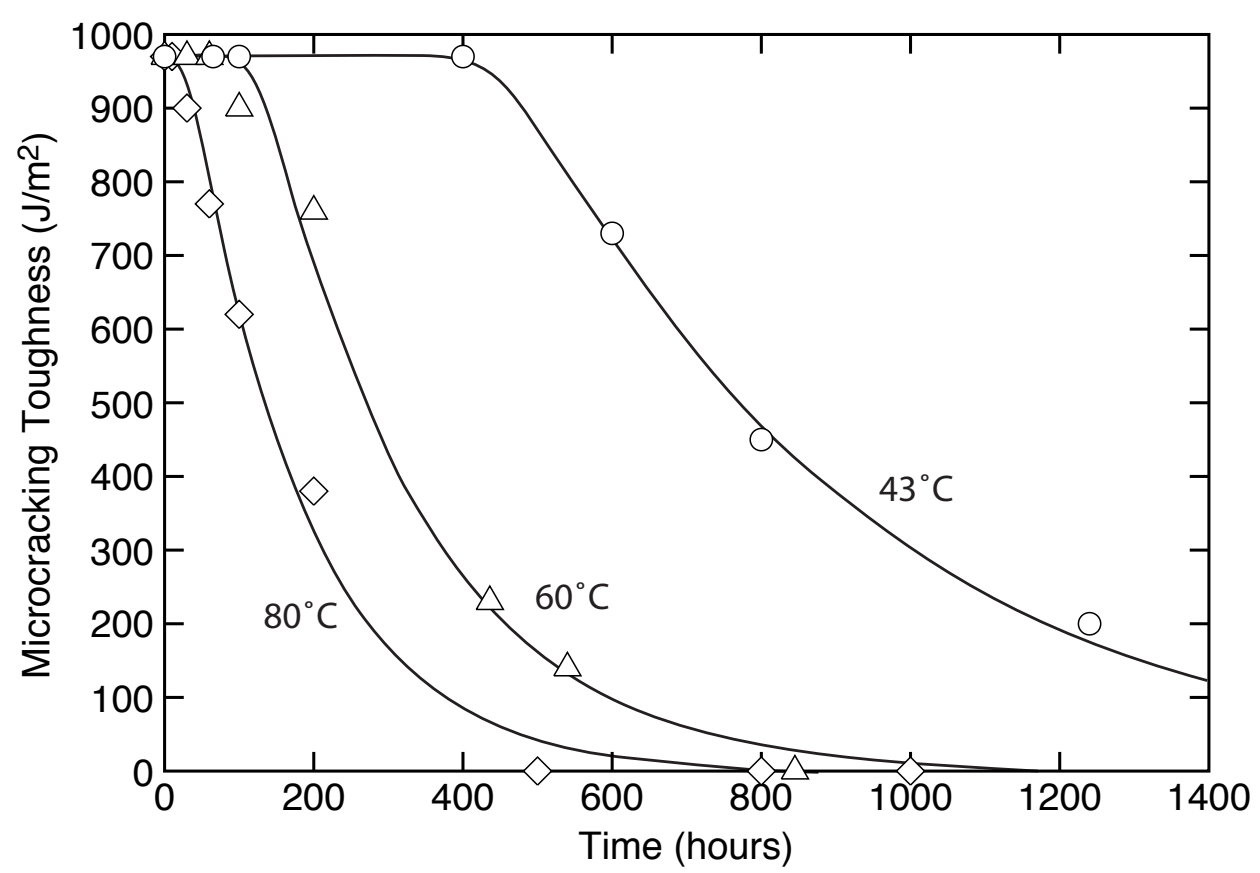

Fig. 4. The microcracking toughness, $G_{m c}$ as a function of aging time for Avimid ${ }^{\circledR}$ K3B/IM7 laminates while immersed in water, but aged at various temperatures. The smooth lines are fits to first-order hydrolysis analysis with threshold water concentration for the onset of degradation.

Table I. Diffusion constant etc. Water content in weight percent

\begin{tabular}{lcccccc}
\hline Conditions & {$\left[\mathrm{H}_{2} \mathrm{O}(\infty)\right]$} & {$\left[\mathrm{H}_{2} \mathrm{O}\right]_{\text {thres }}$} & $k\left(\frac{1}{h r-\%}\right)$ & $k^{*}(\infty)\left(\frac{1}{h r}\right)$ & $D\left(\frac{\mathrm{m}^{2}}{\mathrm{sec}}\right)$ & $t_{\text {thres }}(\mathrm{hr})$ \\
\hline $80^{\circ} \mathrm{C}$, immersed & 0.432 & 0.230 & 0.031 & $6.26 \times 10^{-3}$ & $8.3 \times 10^{-13}$ & 10.9 \\
$80^{\circ} \mathrm{C}, 76 \% \mathrm{RH}$ & 0.376 & 0.230 & 0.031 & $4.53 \times 10^{-3}$ & $8.3 \times 10^{-13}$ & 14.0 \\
$80^{\circ} \mathrm{C}, 50 \% \mathrm{RH}$ & 0.280 & 0.230 & 0.031 & $1.55 \times 10^{-3}$ & $8.3 \times 10^{-13}$ & 25.0 \\
$60^{\circ} \mathrm{C}$, immersed & 0.440 & 0.403 & 0.130 & $4.81 \times 10^{-3}$ & $4.1 \times 10^{-13}$ & 90.0 \\
$43^{\circ} \mathrm{C}$, immersed & 0.420 & 0.417 & 0.730 & $2.19 \times 10^{-3}$ & $2.0 \times 10^{-13}$ & 400 \\
\hline
\end{tabular}

started to decrease. Both the threshold time and the diffusion constant for water uptake were functions of temperature (see Table I).

\section{PETI-5/IM7 Laminates}

Similar aging experiments were done for PETI-5/IM7 laminates immersed in water at $80^{\circ} \mathrm{C}$. The raw microcracking results together with fits to Eq. (2) are given in Fig. 5. The ply properties and $\Delta T=-225^{\circ} \mathrm{C}$ for PETI-5/IM7 was the same as for K3B/IM7 except the ply thickness was $0.142 \mathrm{~mm}$. Note that the fitting procedure focused on the data at high crack density because it gives more reliable results for $G_{m c}$. The deviations at low crack density can be fit by accounting for statistical variations in the toughness property but that procedure does not give any new information about overall toughness properties or change the mean value of $G_{m c}$ [4]. The toughness of unaged PETI5/IM7 was very close to the toughness of unaged Avimid ${ }^{\circledR}$ K3B/IM7. Upon aging, however, the drop in toughness for PETI-5/IM7 was much slower. For the first 1000 hours of aging 


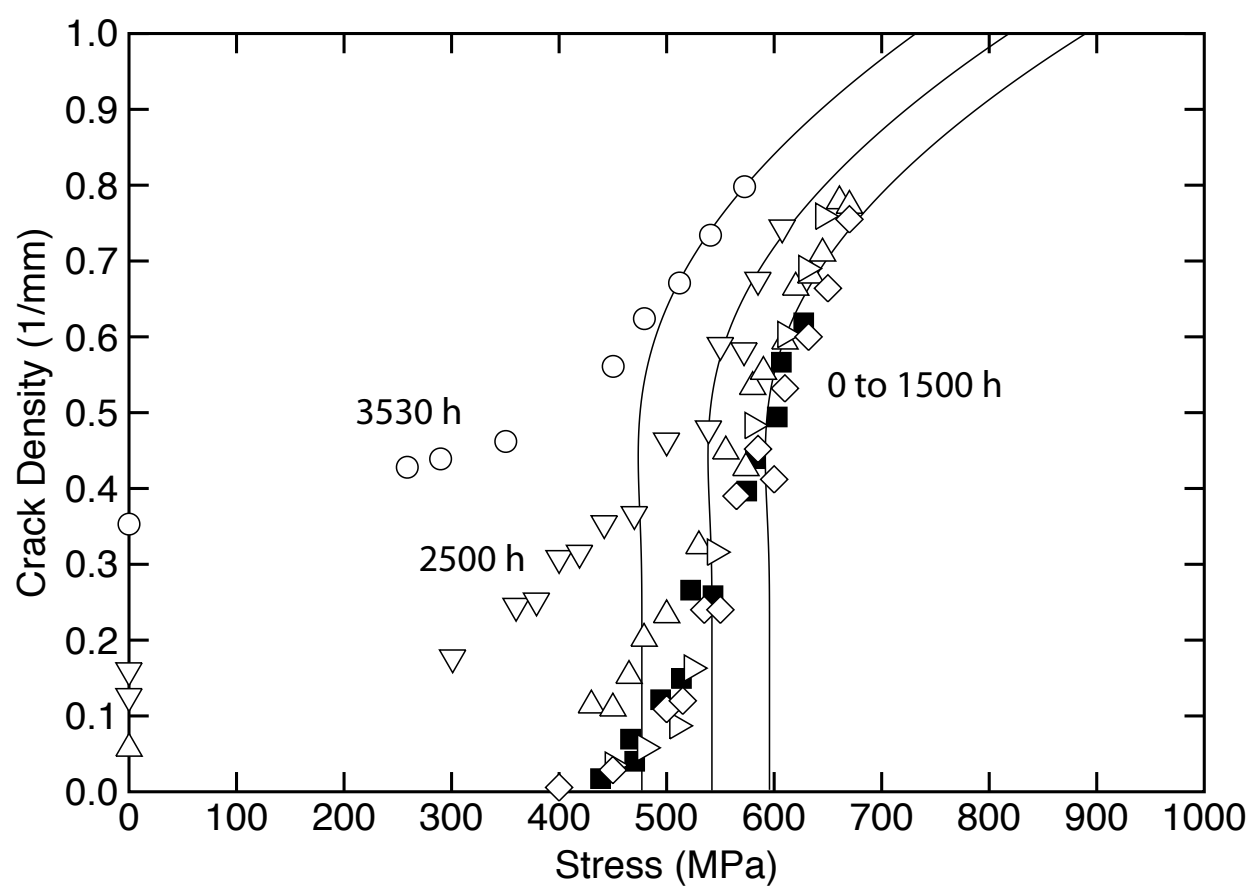

Fig. 5. The density of microcracks as a function of applied stress for unaged (filled symbols) and aged PETI5/IM7 laminates. The aging was for various amounts of time at $80^{\circ} \mathrm{C}$ while immersed in water. The smooth lines are fits to microcracking theory which were used to determine microcracking toughness as function of aging time.

there was no noticeable drop in toughness. After 1500 hours (triangles) the raw data showed a slight shift, but it was difficult to resolve any change in toughness. Finally after 2500 hours or 3530 hours, there was a clear decrease in toughness. By 3500 hours, it had only dropped $30 \%$. The measured toughness as a function of aging time is plotted in Fig. 6 along with the previous Avimid ${ }^{\circledR}$ K3B/IM7 results for comparison. Because aging under the harshest conditions we used (immersed at $80^{\circ} \mathrm{C}$ ) was slow for PETI-5/IM7 laminates, we did not do experiments at lower humidities or lower temperatures. The modeling of degradation due to aging in the next section, was therefore confined to the Avimid ${ }^{\circledR}$ K3B/IM7 results.

\section{Discussion}

\section{Simple Hydrolysis Kinetics Model}

For all hygrothermal conditions and for both polyimide systems, the microcracking toughness decreased with time. The decrease was probably caused by hydrolysis of the polyimide resins [13]. There appears, however, to be a threshold effect, which was especially apparent at lower temperatures. The toughness remained constant a short amount of time before starting to decrease. In this section, we suggest a simple first-order kinetics analysis for the degradation process. We assumed the rate of degradation was proportional to the water content. To account for the threshold effect, we assumed that the first water goes into sites that do not cause damage and only the later water causes hydrolysis. Thus, the first order degradation is first order in total water concentration $(\%$ weight gain) above some threshold concentration [14]. 


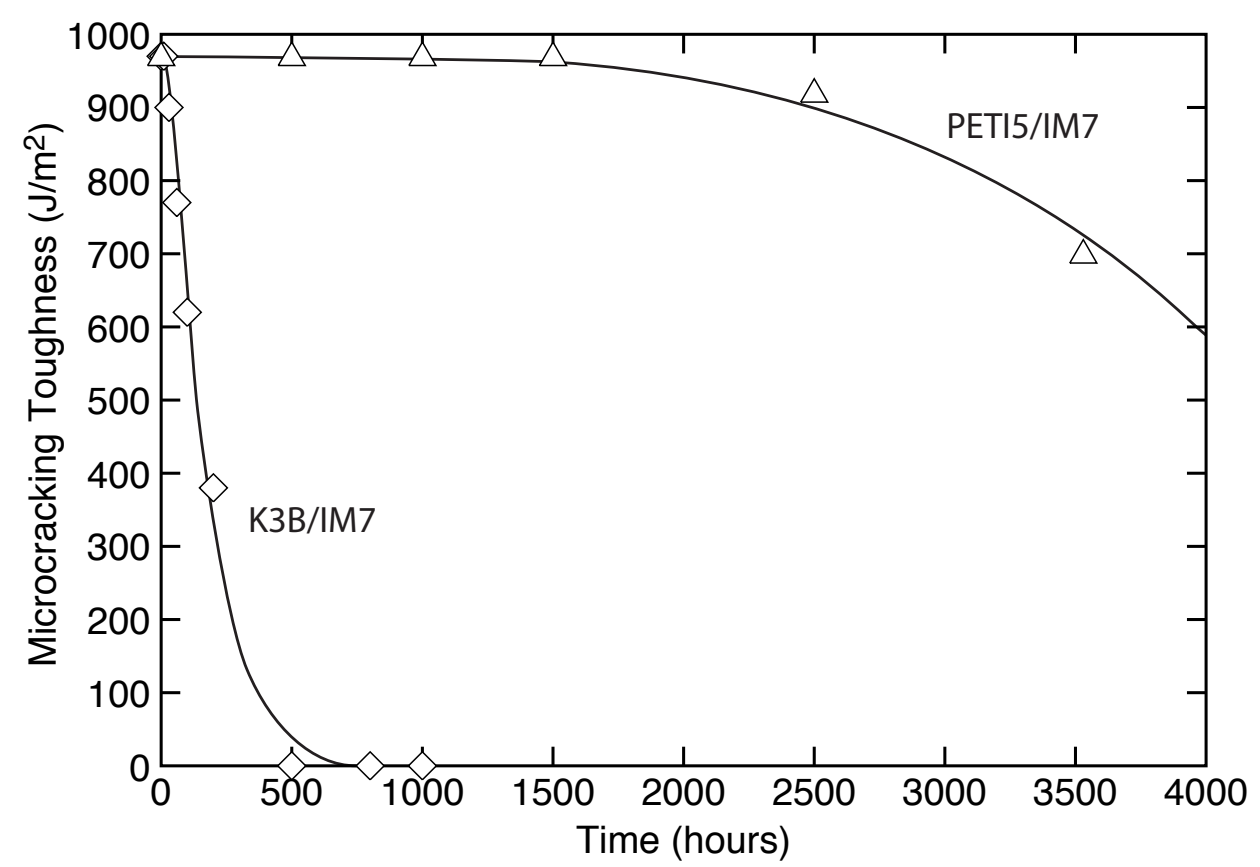

Fig. 6. A comparison of the microcracking toughness, $G_{m c}$, as a function of aging time for PETI-5/IM7 laminates and Avimid ${ }^{\circledR} \mathrm{K} 3 \mathrm{~B} / \mathrm{IM} 7$ laminates at $80^{\circ} \mathrm{C}$ while immersed in water. The smooth lines are fits to first-order hydrolysis analysis with threshold water concentration for the onset of degradation.

By the first order kinetics with a threshold effect, the rate in decrease in toughness is

$$
\frac{d G_{m c}}{d t}= \begin{cases}0 & \text { for } t \leq t_{\text {thres }} \\ -k\left(\left[H_{2} O(t)\right]-\left[H_{2} O\right]_{\text {thres }}\right) G_{m c}(t) & \text { for } t>t_{\text {thres }}\end{cases}
$$

where $k$ is a rate constant, $\left[\mathrm{H}_{2} \mathrm{O}(t)\right]$ is the water weight gain as a function of time, $\left[\mathrm{H}_{2} \mathrm{O}\right]_{\text {thres }}$ is the threshold concentration below which no degradation occurs, and $t_{\text {thres }}$ is the time for the water weight gain to reach $\left[\mathrm{H}_{2} \mathrm{O}\right]_{\text {thres }}$. This degradation rate integrates to

$$
G_{m c}(t)= \begin{cases}G_{m c}^{0} & \text { for } t \leq t_{\text {thres }} \\ G_{m c}^{0} \exp \left(-k \int_{t_{\text {thres }}}^{t}\left(\left[H_{2} O(t)\right]-\left[H_{2} O\right]_{\text {thres }}\right) d t\right) & \text { for } t>t_{\text {thres }}\end{cases}
$$

where $G_{m c}^{0}$ is the microcracking toughness before aging.

In this model, the toughness thus depends on the integrated exposure to water above some threshold water concentration. This integral term is illustrated in Fig. 7 as the shaded area bounded by the water diffusion curve, the threshold water concentration, and the current time. For a given set of hygrothermal aging conditions, the parameters for fitting experimental results are the diffusion constant $(D)$, the threshold condition (which is determined by the $t_{\text {thres }}$ or calculated from diffusion analysis and $\left.\left[\mathrm{H}_{2} \mathrm{O}\right]_{\text {thres }}\right)$, and the constant $k$. The diffusion constant can be determined from water weight gain experiments vs. time. The $\left[\mathrm{H}_{2} \mathrm{O}\right]_{\text {thres }}$ and $k$ parameters can then be determined by fitting to experimental results for $G_{m c}(t)$. In practice, the $t_{\text {thres }}$ and corresponding $\left[\mathrm{H}_{2} \mathrm{O}\right]_{\text {thres }}$ terms can be closely approximated from the onset of degradation and thus $k$ is the main parameter that is adjusted for fit. The smooth curves in Figs. 3 and 4 are fits of Eq. (9) to experimental results.

The parameters used to fit experimental results are given in Table I. The results for all humidities at a single temperature could be fit with the same values for $k,\left[\mathrm{H}_{2} \mathrm{O}\right]_{\text {thres }}$, and $D$; these 
parameters did change, however, with temperature. The threshold times $\left(t_{\text {thres }}\right)$ depended on temperature and humidity, but because $\left[\mathrm{H}_{2} \mathrm{O}\right]_{\text {thres }}$ and $\mathrm{D}$ are independent of humidity, the humidity dependence of $t_{\text {thres }}$ can be calculated by diffusion analysis. At $80^{\circ} \mathrm{C}$, the threshold water weight gain was determined to be $0.23 \%$. This result predicts that for relative humidities too low to get water content above $0.23 \%$, there should be no degradation in toughness. This prediction agrees with the results at RH 26\% — at least for the first 1000 hours, the results at this low humidity showed no degradation in toughness corresponding to the fact that the saturation water weight was only $0.121 \%$ or never exceeded $\left[\mathrm{H}_{2} \mathrm{O}\right]_{\text {thres }}$.

\section{Master Plot Analysis}

The experimental results for hygrothermal aging of polyimide matrix composite laminates showed that all aging conditions caused degradation in the laminate microcracking toughness. If the results at lower humidity and lower temperature, where degradation was slower, can be related to the water immersion results at higher temperature, where degradation was faster, a high-temperature, waterimmersion test could be developed as an accelerated method for predicting long-term durability of composite materials. In this section, a master plot of hygrothermal aging is constructed which plots a universal curve for $G_{m c}(t)$ as a function of an effective time. The effective time scale was calculated by correspondence of equal degradation conditions based on the degradation model in the previous section. Such a master plot characterizes a single material and might be useful for predicting the extent of degradation of that same material under any arbitrary hygrothermal conditions.

By the form of Eq. (9), any two samples that have experienced the same integrated exposure to water should have the same degradation in toughness. Thus, it should be possible to derive a master plot for hygrothermal degradation by shifting results at any temperature and humidity to the equivalent exposure at some reference temperature and humidity. In other words, the effective time, $t_{e f f}$, at reference conditions can be found by solving

$$
\int_{t_{\text {thres }}^{\text {ref }}}^{t_{\text {eff }}} k^{*}\left(t, T_{\text {ref }}, R H_{\text {ref }}\right) d t=\int_{t_{\text {thres }}^{T, R H}}^{t} k^{*}(t, T, R H) d t
$$

for $t_{\text {eff }}$ or solving for the time when the integrated area under reference conditions (temperature

$T_{\text {ref }}$, humidity $R H_{\text {ref }}$, and threshold time $t_{\text {thres }}^{\text {ref }}$ ) is equal to the integrated area under observation conditions (temperature $T$, humidity $R H$, and threshold time $t_{\text {thres }}^{T, R H}$ ). Here $k^{*}(t, T, R H)$ is a net degradation rate defined by

$$
k^{*}(t, T, R H)=k(T)\left(\left[H_{2} O\right](t, T, R H)-\left[H_{2} O(T)\right]_{t h r e s}\right)
$$

From experimental observations, both the constant $k(T)$ and the threshold water concentration, $\left[\mathrm{H}_{2} \mathrm{O}(\mathrm{T})\right]_{\text {thres }}$, depend only on temperature while the experimental data for $\left[\mathrm{H}_{2} \mathrm{O}\right](t, \mathrm{~T}, \mathrm{RH})$ depend on time, temperature, and humidity.

A given set of experimental results for water uptake at various temperatures and humidities can be substituted into Eq. (10) and numerically integrated to construct a master plot for hygrothermal aging. Alternatively, if the diffusion constant is known as a function of temperature, it would be possible to calculate the water uptake curves and use the calculated results to numerically solve Eq. (10). Both of these approaches can be used, but a simpler approach also worked well. We observed that the time for significant degradation was typically much longer than the time to reach 


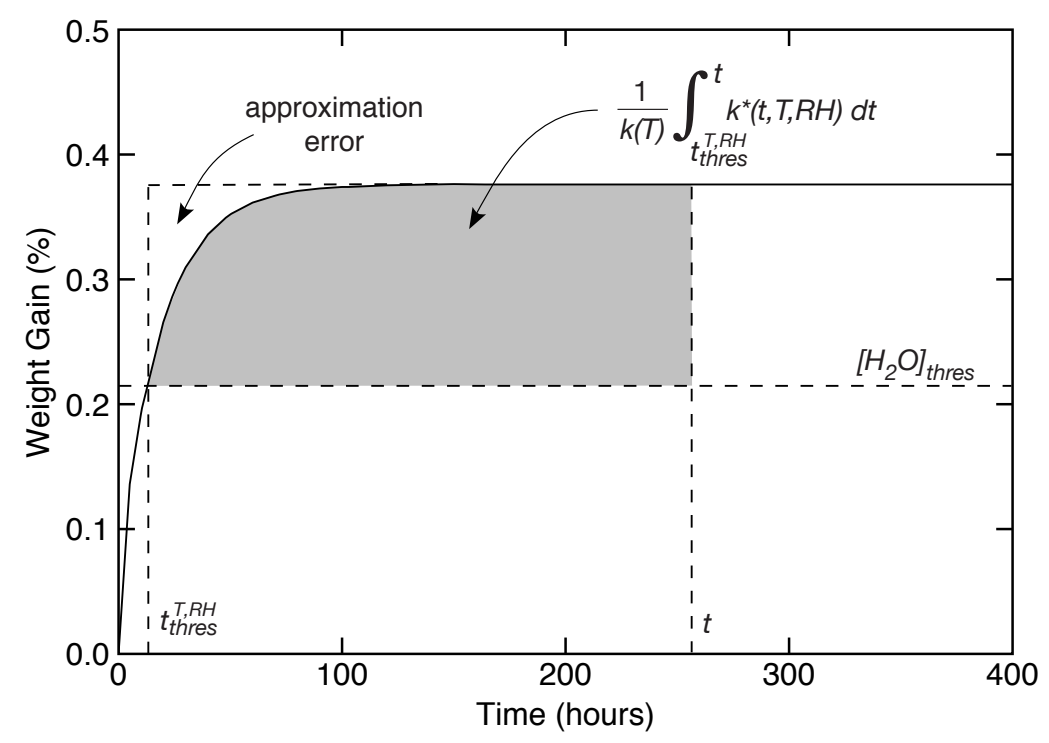

Fig. 7. The extent of hydrolysis damage was assumed to be proportional to the total water exposure above a threshold water concentration. The total exposure at time $t$ is the shaded area bounded by the water uptake curve, the threshold water content, $\left[\mathrm{H}_{2} \mathrm{O}\right]_{\text {thres }}$ between the times $t_{\text {thres }}$ and $t$. The "approximation error" is the white area between the water uptake curve and the dotted rectangle surrounding the shaded area.

saturation water concentration. Under these conditions, $t_{\text {eff }}$ and $t$ are both much greater than the threshold times at those conditions and Eq. (10) can be written exactly as

$$
k^{*}\left(\infty, T_{\text {ref }}, R H_{\text {ref }}\right)\left(t_{\text {eff }}-t_{\text {thres }}^{\text {ref }}\right)-k\left(T_{\text {ref }}\right) \Delta_{\text {ref }}=k^{*}(\infty, T, R H)\left(t-t_{\text {thres }}^{T, R H}\right)-k(T) \Delta
$$

where $k^{*}(\infty, T, R H)$ is the time-independent value of $k^{*}(t, T, R H)$ after reaching water saturation and $\Delta_{r e f}$ and $\Delta$ are the small (positive), approximation errors (the equation is exact because all approximation errors are included in the $\Delta_{\text {ref }}$ and $\Delta$ terms). The approximation error is defined as the difference between the area of the dotted rectangle enclosing the shaded area in Fig. 7 and the true integrated error (i.e., shaded area in Fig. 7); the approximation error is labeled in Fig. 7. This equation can be solved for $t_{\text {eff }}$ to give

$$
t_{e f f}=t_{e f f}^{\text {approx }}+\frac{k\left(T_{r e f}\right) \Delta_{r e f}-k(T) \Delta}{k^{*}\left(\infty, T_{r e f}, R H_{r e f}\right)}
$$

where $t_{\text {eff }}^{\text {approx }}$ is an approximate effective time given by

$$
t_{\text {eff }}^{\text {approx }}=t_{\text {thres }}^{\text {ref }}+\frac{k^{*}(\infty, T, R H)}{k^{*}\left(\infty, T_{\text {ref }}, R H_{\text {ref }}\right)}\left(t-t_{\text {thres }}^{T, R H}\right)
$$

We calculated effective times for our experiments using both the more-accurate Eq. (10) (with calculated uptake curves using temperature-dependent diffusion constant input) and the approximate Eq. (14). At constant temperature with reference conditions of water immersion, the reference 


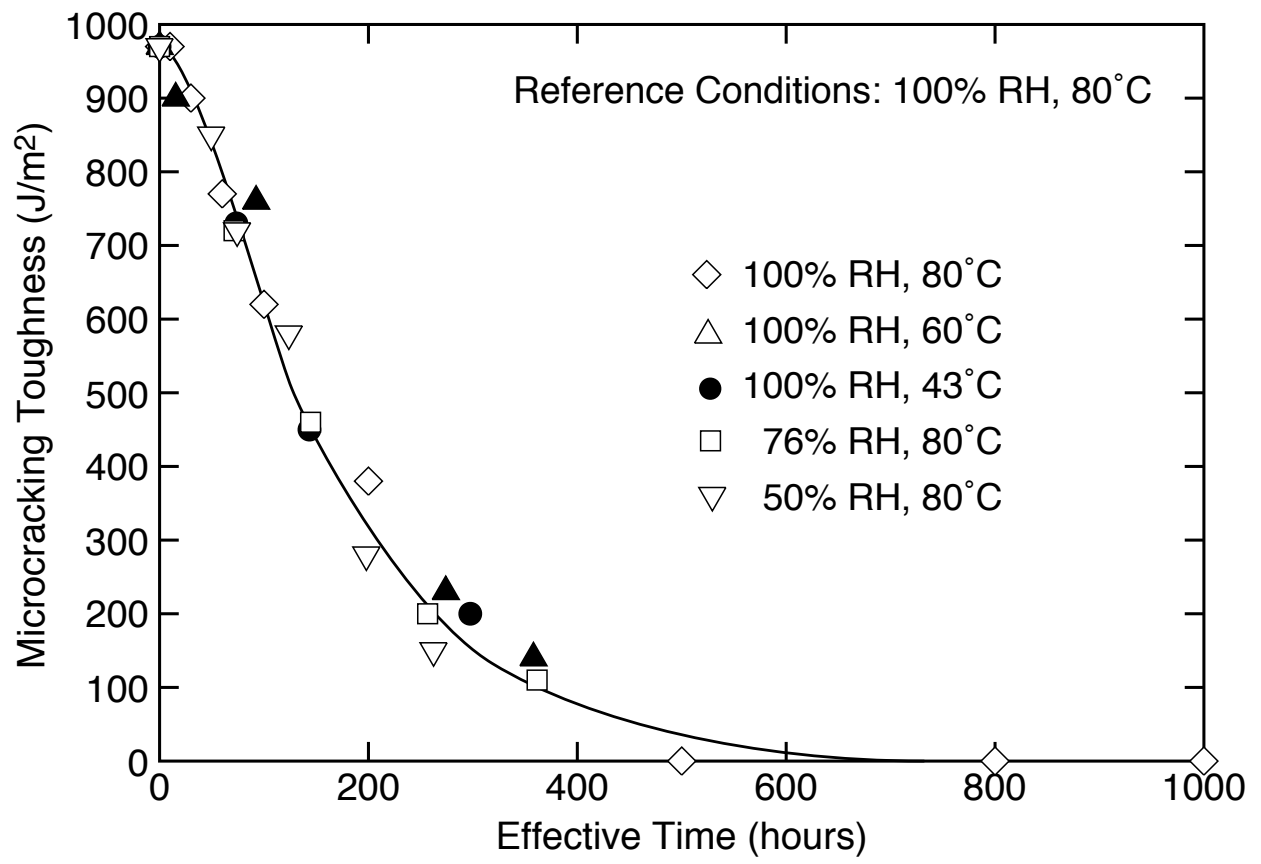

Fig. 8. A hygrothermal aging master plot for Avimid ${ }^{\circledR}$ K3B/IM7 laminates. The reference conditions were water immersion at $80^{\circ} \mathrm{C}$. The effective times for experiments at other conditions were calculated as described in the paper.

approximation error, $\Delta_{r e f}$, will be similar in magnitude, but always larger than the reduced humidity error, $\Delta$. For sufficiently long times, the error terms are small plus the error difference in Eq. (13) results in some cancellation of error. The net result is that $t_{\text {eff }}^{\text {approx }}$ was always less than $t_{\text {eff }}$, but the differences were small. For most aging times, the approximate time was within $10 \%$ of the more accurate analysis. Clearly the approximations are worse and thus the differences are larger for short times, but the results at short times are of less interest to the development of accelerated test methods. At different tempertures, $t_{\text {eff }}^{\text {approx }}$ may be smaller or larger than $t_{\text {eff }}$ depending on the temperature dependencies of the various parameters $(k(T)$ and $\Delta)$. At reduced temperature $t_{\text {eff }}^{\text {approx }}$ was within $5 \%$ of $t_{\text {eff }}$ for longer times and never off by more than $10 \%$ at even the shortest times. The approximate analysis was used here for derivation of a master plot. We expect that Eq. (14) will normally be adequate for other materials unless degradation at either the reference or test condition is very rapid, such that a signficant amount of degradation occurs before water saturation.

Figure 8 gives a master plot for all our results on Avimid ${ }^{\circledR}$ K3B/IM7 laminates. The reference conditions were water immersion at $80^{\circ} \mathrm{C}$; the effective times were calculated using Eq. (14). Shifting by Eq. (14) requires knowledge of the temperature and humidity dependence of $k^{*}(t, T, R H)$ and the threshold times for degradation; the values used to construct this master plot are given in Table I. The threshold degradation times can be observed in experiments or calculated by diffusion analysis given $\left[\mathrm{H}_{2} \mathrm{O}(\mathrm{T})\right]_{\text {thres }}$ and the temperature dependence of the diffusion constant (these terms are also given in Table I). The net degradation rate of $k^{*}(t, T, R H)$ probably provides a better indication of degradation than the separate terms $k(T)$ and $\left[H_{2} O(T)\right]_{\text {thres }}$. The temperature dependence of $k^{*}(t, T, R H)$ for water-immersion conditions from our limited experiments can be described by an apparent activation energy of $26 \mathrm{~kJ} / \mathrm{mol}$ which is very close to the apparent activation energy from spontaneous microcracking formation experiments [1]. 
Requiring knowledge of the humidity dependence of $k^{*}(t, T, R H)$ is a disadvantage of using a net degradation rate, but because $k(T)$ and $\left[H_{2} O(T)\right]_{\text {thres }}$ were independent of humidity and $\left[H_{2} O(\infty, T)\right]$ scaled with effective humidity, $k^{*}(t, T, R H)$ at constant temperature, but at any humidity, can be calculated from its value under water immersion $(\mathrm{RH}=100 \%)$ using

$$
\frac{k^{*}(\infty, T, R H)}{k^{*}(\infty, T, 100 \%)}=\frac{R H-F(T)}{1-F(T)}
$$

where $R H$ is the effective relative humidity and $F(T)$ is the ratio of the threshold water concentration, $\left[H_{2} O(T)\right]_{\text {thres }}$, to the saturation water weight gain, $\left[H_{2} O(\infty, T)\right]$, when immersed in water. With this result, the approximate effective time can be written as

$$
t_{\text {eff }}^{\text {approx }}=t_{\text {thres }}^{\text {ref }}+\frac{K(T)}{K\left(T_{\text {ref }}\right)} \frac{R H-F(T)}{1-F(T)}\left(t-t_{\text {thres }}^{T, R H}\right)
$$

where $K(T)$ is shorthand for $K(T)=k^{*}(\infty, T, 100 \%)$ which is a function only of temperature. This equation assumes the reference humidity conditions are for water immersion.

Equation (16) is a potential equation for predicting degradation at any temperature and humidity from observed degradation at some reference conditions. In other words, Eq. (16) can be basis for accelerated characterization of the hygrothermal stability of composite laminates. The minimum experiments to characterize a material are to determine $K(T)$ and $F(T)$ as a function of temperature. These terms can be determined in accelerated tests done under water immersion instead of the slower tests at reduced humidity. If $K(T)$ and $F(T)$ are measured at a few temperatures, the results at other temperatures can be determined by extrapolation. The analysis, however, would only be expected to work over a temperature range where the mechanism of degradation remains hydrolysis degradation. The threshold degradation time, $t_{\text {thres }}^{T, R H}$, depends on experiments at reduced humidity. This term, however, can be calculated by diffusion analysis given the temperature dependence of the diffusion constant, $D(T)$, and the threshold water concentration, $\left[H_{2} O(T)\right]_{\text {thres }}$. Both of these terms depend only on temperature and thus $t_{\text {thres }}^{T, R H}$ can also be determined from water immersion experiments.

\section{Conclusions}

Polyimide-matrix composites show degradation in toughness when exposed to water and high temperature. All experimental results can be fit to simple first-order kinetics by assuming there is some threshold water concentration below which no degradation occurs. The rate constants calculated from these fits can be used to shift all results to a master plot for hygrothermal aging. By extrapolating rate constants to other temperatures and humidities it is possible to use the master plot to predict hygrothermal degradation at any constant temperature and humidity. By calculating the integrated exposure to water under any hygrothermal conditions, such as hygrothermal cycling conditions, it might also be possible to use the master plot to predict the extent of toughness degradation caused by more complicated conditions. An underlying assumption of the model is a single degradation mechanism; uncertainties would therefore exist if extrapolations for master plot calculation were extended significantly outside the temperature range of the basic characterization experiments.

Construction of hygrothermal-aging master plots for other material systems is a potential accelerated test method for characterizing the hygrothermal stability of composite laminates. The minimal experiments are to measure toughness degradation at the reference temperature while immersed in water and at several other temperatures while immersed in water. Such results at several 
temperatures can be used to give the temperature dependence of $K(T)$ and $F(T)$. The onset of

degradation (or the threshold time $t_{\text {thres }}^{T, R H}$ ) can be calculated from the temperature dependence of the diffusion constant, $D(T)$ and the threshold water concentration, $\left[H_{2} O(T)\right]_{\text {thres }}$, both of which can also be determined in accelerated water-immersion experiments

\section{Acknowledgements}

This work was supported, in part, by a grant from the Mechanics of Materials program of the National Science Foundation (CMS-9713356), and, in part, under a Boeing contract NAMP-12941544. The authors also thank Mike Grayson for many helpful discussions.

\section{References}

1. Kim, H. W., M. A. Grayson, and J. A. Nairn, "The Effect of Hygrothermal Aging on the Microcracking Properties of Some Carbon Fiber/Polyimide Laminates," Adv. Comp. Letters, 4, 185 (1995).

2. Greenspan, L., "Humidity Fixed Points of Binary Saturated Aqueous Solutions," Journal of Research of the National Bureau of Standards A. Physics and Chemistry, 81A, 89 (1977).

3. Wexler, A., and S. Hasegawa, "Relative Humidity-Temperature Relationships of Some Saturated Salt Solutions in The Temperature Range 0 to $50^{\circ} \mathrm{C}$," Journal of Research of the National Bureau of Standards, 53, 19 (1954).

4. Nairn, J. A., "Matrix Microcracking in Composites," in: Polymer Matrix Composites, eds., R. Talreja and J.-A. E. Manson, Vol. 2 of Comprehensive Composite Materials, Elsevier Science, pp. 403-432 (2000).

5. Nairn, J. A., "Applications of Finite Fracture Mechanics for Predicting Fracture Events in Composites," Fifth Int'l Conf. on Deformation and Fracture of Composites, London, UK, March 18-19, 1999.

6. Nairn, J. A., and S. Hu, "Micromechanics of Damage: A Case Study of Matrix Microcracking," in: Damage Mechanics of Composite Materials, eds., Ramesh Talreja, Elsevier, Amsterdam, pp. 187-243 (1994).

7. Nairn, J. A., S. Hu, and J. S. Bark, "A Critical Evaluation of Theories for Predicting Microcracking in Composite Laminates," J. Mat. Sci., 28, 5099 (1993).

8. J. A. Nairn, unpublished results (displacement control).

9. McCartney, L. N., "Predicting Transverse Crack Formation in Cross-Ply Laminates," Comp. Sci. \& Tech., 58, 1069 (1998).

10. Nairn, J. A., "Fracture Mechanics of Composites with Residual Thermal Stresses," J. Appl. Mech., 64, 804 (1997).

11. Hashin, Z., "Analysis of Cracked Laminates: A Variational Approach," Mech. of Mat., 4, 121 (1985).

12. Nairn, J. A., "Microcracking, Microcrack-Induced Delamination, and Longitudinal Splitting of Advanced Composite Structures," NASA Contractors Report CR 44721992.

13. Delasi, R., and J. Russel, "Aqueous Degradation of Polyimides," Journal of Applied Polymer Science, 15, 2965 (1971).

14. Nairn, J. A., and M.-H. Han, "Hygrothermal Aging of Polyimide Matrix Composite Laminates," Proc. Int. Conf. Comp. Mat. 12, Paris, France, July 5-9, 1999. 